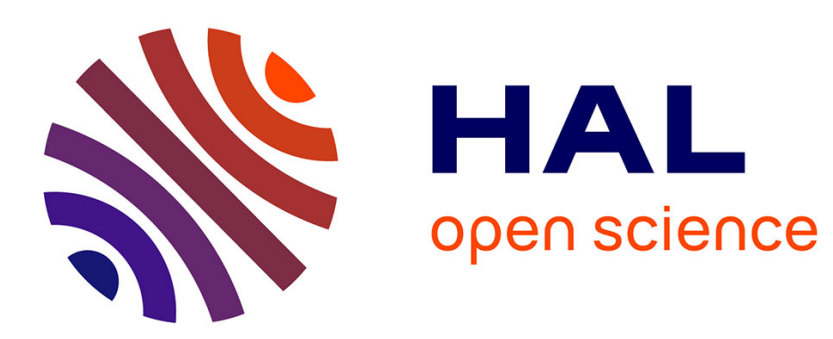

\title{
TEM and EXAFS study of Ar+ implanted Mo thin films
}

J. Dinhut, Philippe Chartier

\section{To cite this version:}

J. Dinhut, Philippe Chartier. TEM and EXAFS study of Ar+ implanted Mo thin films. Journal de Physique IV Proceedings, 1994, 04 (C3), pp.C3-273-C3-277. 10.1051/jp4:1994337 . jpa-00252534

\section{HAL Id: jpa-00252534 https://hal.science/jpa-00252534}

Submitted on 1 Jan 1994

HAL is a multi-disciplinary open access archive for the deposit and dissemination of scientific research documents, whether they are published or not. The documents may come from teaching and research institutions in France or abroad, or from public or private research centers.
L'archive ouverte pluridisciplinaire HAL, est destinée au dépôt et à la diffusion de documents scientifiques de niveau recherche, publiés ou non, émanant des établissements d'enseignement et de recherche français ou étrangers, des laboratoires publics ou privés. 


\title{
TEM and EXAFS study of $\mathrm{Ar}^{+}$implanted Mo thin films
}

\author{
J.F. DINHUT and P. CHARTIER
}

Laboratoire de Métallurgie Physique, URA 131 du CNRS, Université de Poitiers, 40 Avenue du Recteur Pineau, 86022 Poitiers cedex, France

\begin{abstract}
TEM observations and CEEXAFS measurements of $\mathrm{Ar}^{+}$implanted molybdenum films were performed. The appearance of a fcc phase is clearly identified with the two characterisation techniques and the lattice parameter is shown to be $\mathrm{a}=0.420 \mathrm{~nm}$. No solid argon bubbles can be detected. An interpretation is given based on the possible internal stresses created by $\mathrm{Ar}^{+}$implantation.

\section{Introduction}

Thin films are extensively used in order to improve the surface properties of various materials and particularly the mechanical properties such as hardness, wear resistance or corrosion. Ion implantation is a powerful technique to introduce modifications of the thin films surface as well as structural transformations. In this paper, using Transmission Electron Microscopy (TEM) and Conversion Electron Extended X-ray Absorption Fine Structure (CEEXAFS), we investigate the phase transformation of molybdenum film from body centered cubic (bcc) to face centered cubic (fcc) created by ion implantation at room temperature.
\end{abstract}

\section{Experimental details}

Mo films are evaporated using a conventional electron-gun technique at room temperature. The deposition apparatus described in detail elsewhere $(1)$ consists in an UHV chamber equipped with automatically controlled electron guns. The pressure is $10^{-7} \mathrm{~Pa}$ and is always lower than $10^{-6} \mathrm{~Pa}$ during deposition. The total film thickness measured by a calibrated quartz crystal oscillator is $70 \mathrm{~nm}$. Samples were deposited on microscope grids covered with amorphous carbon film for TEM observations and on quartz for CEEXAFS measurements. In order to obtain homogeneous deposition substrates are rotating during evaporation. With this procedure specimens are directly observable by both TEM and CEEXAFS. The $\mathrm{Ar}^{+}$ion implantation is performed at $300 \mathrm{~K}$ using very low currents in order to avoid beam heating of the targets. The pressure in the implantation chamber is about $5.10^{-6} \mathrm{~Pa}$. The characteristic parameters have been calculated using TRIM91 computer code (2). Homogeneous damage profile is obtained over the whole sample thickness for a dose of about $10^{16} \mathrm{Ar}^{+}$ions per $\mathrm{cm}^{2}$ accelerated at $100 \mathrm{keV}$. The projected range is centered at $42 \mathrm{~nm}$ and the longitudinal straggling is about $28 \mathrm{~nm}$ wide.

The TEM experiments are performed at the Laboratory using a Jeol $200 \mathrm{CX}$ electron microscope working at $200 \mathrm{kV}$. The CEEXAFS experiments are performed at LURE (Laboratoire pour l'Utilisation du Rayonnement Electromagnétique, Orsay, France) using the synchrotron radiation from the DCI storage ring operating with an energy of $1.85 \mathrm{GeV}$ and a current of $230 \mathrm{~mA}$. The CEEXAFS spectra are recorded at $80 \mathrm{~K}$ using a cryostat based on the conversion electron detection. This device is described in detail elsewhere $(3,4)$. 
The X-ray absorption spectra are collected over $700 \mathrm{eV}$ above molybdenum K-edge (20000 eV). The EXAFS oscillations are analysed according to a standard procedure described in reference $(5)$. Fourier transform (F.T.) is performed over $40-130 \mathrm{~nm}^{-1} \mathrm{k}$-range using nodal points for the Hamming window function, $\mathrm{k}^{3}$ weighted. By inverse Fourier transform, the EXAFS contribution of the two first shells of the F.T. are isolated. Simulations of the EXAFS function are performed using the widely reported formula $\left({ }^{6}\right)$. From the simulation of EXAFS spectra one can obtain the number of first neighbours $\left(\mathrm{N}_{\mathrm{MoMo}}\right)$, the average interatomic distances $\left(\mathrm{R}_{\mathrm{MoMo}}\right)$ as well as $\sigma_{\mathrm{MoMo}}$ which represents the mean square relative displacement (MSRD) when assuming a Gaussian distribution. The backscattering amplitude and the phase parameters used here are theoretical values calculated by MacKale et al ( 7 ).

\section{Experimental results}

\section{3-1 TEM Results}

Previous TEM experiments $\left(^{8}\right)$ of $\mathrm{Xe}^{+}$implantation in iron and molybdenum films have shown the appearance of solid xenon bubbles with fcc structure, the lattice parameters of such bubbles being $0.560 \mathrm{~nm}$ and $0.600 \mathrm{~nm}$ in the cases of Fe and Mo respectively. Moreover, in molybdenum film, in addition to the classical bcc structure, a fcc Mo phase is observed. From the diffraction pattern, the lattice parameter of this new phase introduced by $\mathrm{Xe}^{+}$ion implantation is about $0.420 \mathrm{~nm}$. In this way, the fcc molybdenum amount is though to be an intermediate structure between the bcc Mo film and the fcc xenon bubbles. The first neighbour distance between the xenon atoms corresponding to the second neighbour distance between the molybdenum atoms in the fcc structure. In figure 1 we present the bright field and the diffraction pattern of the as evaporated molybdenum film. The classical bcc structure is clearly detected with a conventional lattice parameter $(a=0.314 \mathrm{~nm})$. The mean grain size is in the range $5-10 \mathrm{~nm}$ and fissurations could be due to the presence of large residual stresses in the film.
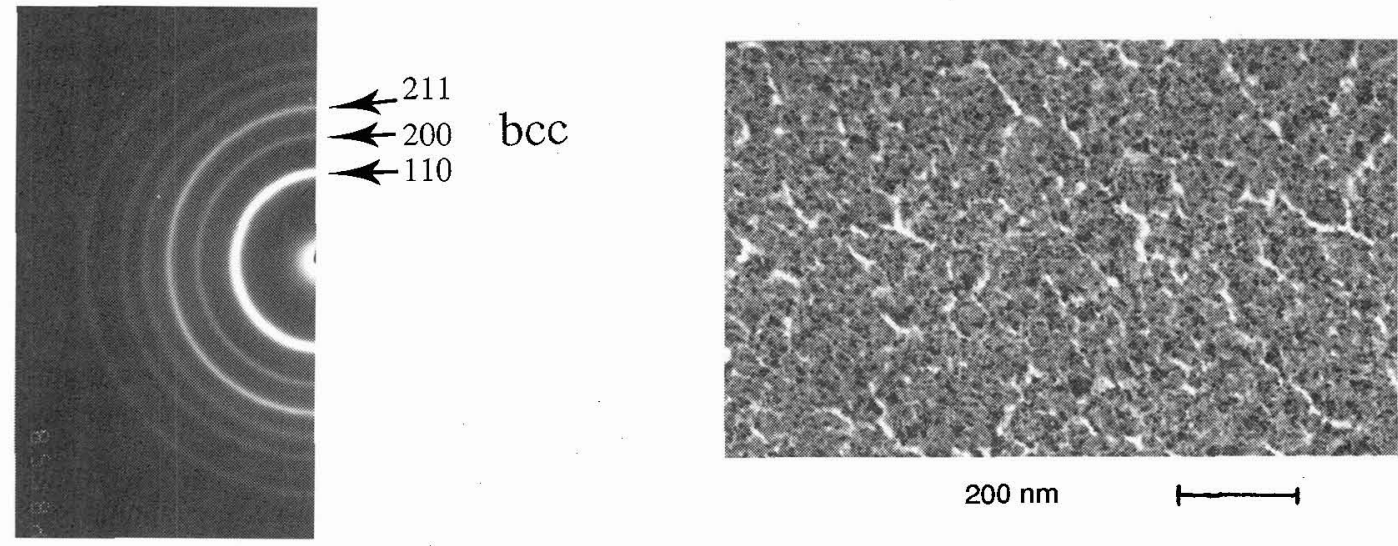

Figure 1 : TEM diffraction pattern and bright field in as evaporated molybdenum thin film.

The TEM observations of $10^{16} \mathrm{Ar}^{+}$implanted Mo film are presented in figure 2 . On the bright field, the grain size distribution is narrower, the mean diameter appears to be larger (about $10 \mathrm{~nm}$ ) and the internal stresses seem removed since fissurations are not observed. From the diffraction pattern rings, in addition to the bcc molybdenum, a fcc structure occurs with a lattice parameter of $a=0.420 \mathrm{~nm}$. The (220) diffraction ring is the main signature of the appearance of the fcc structure. In addition, the first (110) ring of the bcc structure cannot be well separated from both (200) and (111) diffraction rings of the fcc structure. One may point out that this ring is much more intense and wider after $\mathrm{Ar}^{+}$ implantation. These observations are similar to those achieved after $\mathrm{Xe}^{+}$implantation but in the case of $\mathrm{Ar}^{+}$implantation, solid argon bubbles are not detected. 
The use of a carbon layer between the microscope grid and the molybdenum film could lead to the formation of a molybdenum carbide. However, the implanted ion energy is weak enough and $\mathrm{Ar}^{+}$ions do not reach the interfacial region and such mixing is not expected. Moreover, CEEXAFS analysis are performed without carbon layer and fcc structure is also detected as described below.
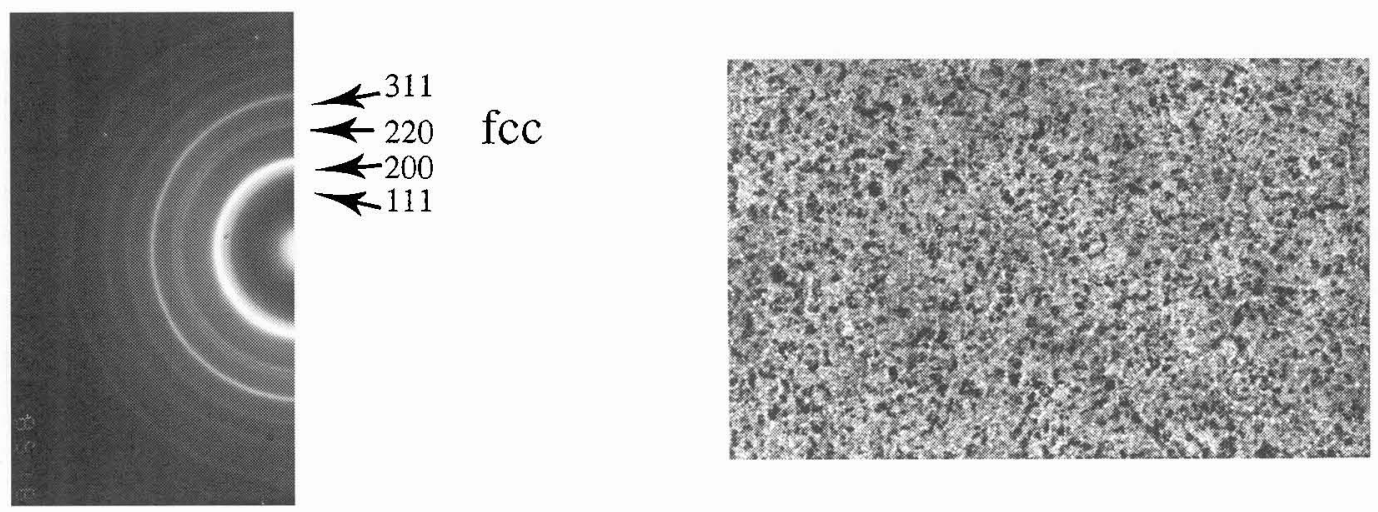

$200 \mathrm{~nm}$

Figure $2:$ TEM diffraction pattern and bright field in Ar+ implanted molybdenum thin film.

\section{3-2 CEEXAFS results}

When comparing the back transformed EXAFS functions (figure 3) obtained for the implanted and non implanted Mo thin films, one observes a decrease of the spectra magnitude after implantation as well as a shift of the nodal points at high energy.

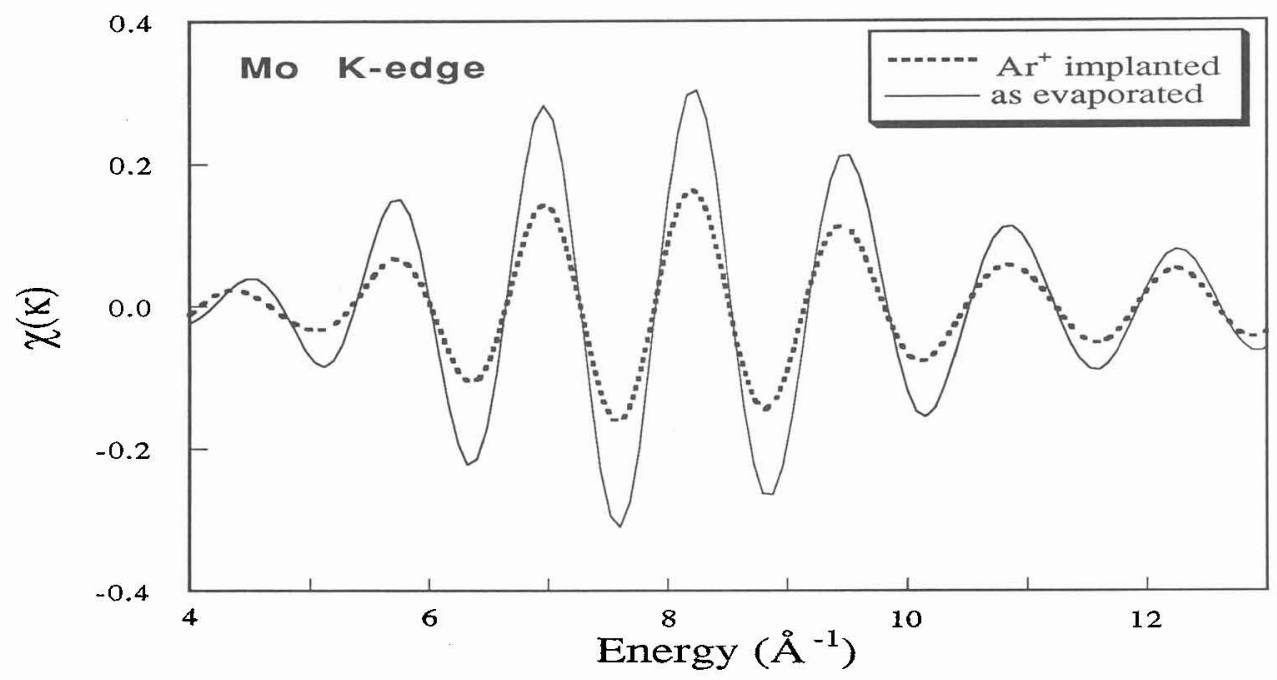

Figure 3 : Back transformed EXAFS function measured on as prepared and Ar ${ }^{+}$implanted molybdenum thin films. 
Simulation of the experimental back transformed EXAFS function of as evaporated and implanted pure molybdenum film have been performed using the standard formula $\left({ }^{\sigma}\right)$. In the case of the as evaporated film, results of the best fit gathered in table 1 indicate a bcc structure (as it is found for bulk specimen) with a lattice constant of $\mathrm{a}=0.314 \mathrm{~nm}$. This result is in complete agreement with the TEM measurements.

Table 1 : Structural parameters extracted from the best fit of the EXAFS functions

\begin{tabular}{|c|c|c|c|c|}
\hline Mo film & Relative $\mathrm{N}_{\mathrm{MoMo}}$ & $\mathrm{R}_{\text {MoMo }}(\mathrm{nm})$ & $\sigma_{\mathrm{MoMo}}(\mathrm{nm})$ & Structure \\
\hline As evaporated & $\begin{array}{ll}1^{\text {st }} \text { neighbours } & 8 \\
2^{\text {nd }} \text { neighbours } & 6\end{array}$ & $\begin{array}{l}0.272 \\
0.314\end{array}$ & $\begin{array}{l}0.070 \\
0.070\end{array}$ & $100 \% \mathrm{bcc}$ \\
\hline $\mathrm{Ar}^{+}$implanted & $\begin{array}{lr}1^{\text {st }} \text { neighbours } & 6 \\
2^{\text {nd }} \text { neighbours } & 4.5 \\
1^{\text {st }} \text { neighbours } & 3\end{array}$ & $\begin{array}{l}0.273 \\
0.313 \\
0.294\end{array}$ & $\begin{array}{l}0.070 \\
0.075 \\
0.075\end{array}$ & $\begin{array}{l}75 \% \text { bcc } \\
25 \% \text { fcc }\end{array}$ \\
\hline
\end{tabular}

In the case of implanted film, no fit had converged when leaving, as floating parameter, the two MSRD factors $\left(\sigma_{\mathrm{MoMo}}\right)$ as well as the two interatomic distances $\left(\mathrm{R}_{\mathrm{MoMo}}\right)$ of the bcc structure. However, the best fit is obtained when adding a third shell centred around $\mathrm{R}_{\mathrm{MoMo}}=0.294 \mathrm{~nm}$ (figure 4).

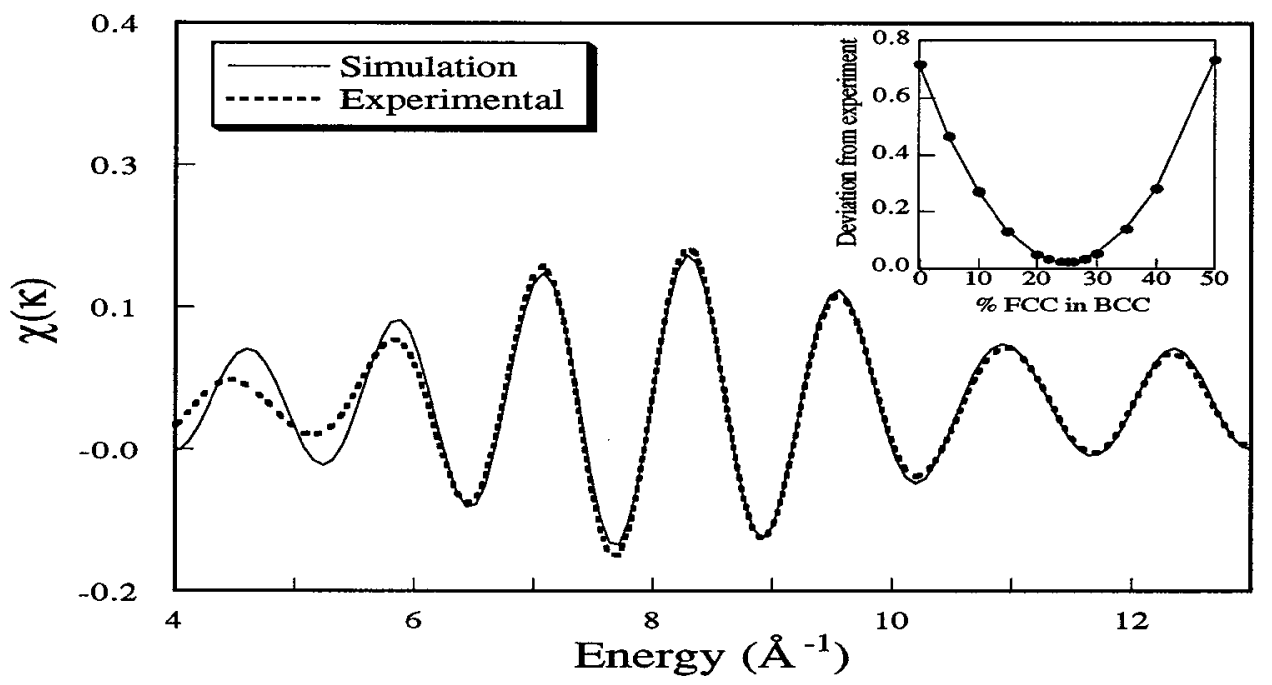

Figure 4 : Best fit of the back transformed EXAFS function measured on Ar ${ }^{+}$implanted molybdenum thin film. Included the deviation between experimental and theoretical signal. 
In fact this supplementary subshell corresponds to the first interatomic distance found in fcc molybdenum (lattice parameter $a=0.416 \mathrm{~nm}$ ). The structural parameters extracted from the best fit are given in table 1. In figure 4, we also present the deviation value between experimental and theoretical spectra as a function of the fcc proportion in bcc matrix. This curve presents a minimum for $25 \%$ of fcc phase in the film. According to the relative coordination number (table 1) we can conclude that the implanted molybdenum film provide the same EXAFS signal as a mixing of $75 \%$ bcc with $25 \%$ fcc.

\section{Discussion}

Both CEEXAFS and TEM results indicate that pure molybdenum evaporated is obtained in the bcc structure as in bulk specimen. We must here remind that evaporated pure molybdenum has already been prepared with the fcc structure $\left({ }^{9}\right)$ using another elaboration device.

The CEEXAFS results show that the $\mathrm{Ar}^{+}$ions implantation induce the formation of the fcc structure among the existing bcc structure. The two structures ( $75 \%$ of bcc with $25 \%$ of fcc) coexist in the whole sample thickness. Indeed, the CEEXAFS technique consists in the detection of the conversion electron escaped from the sample after the X-ray absorption and so is very surface sensitive. We have recently calculated the escaping depth of such electrons for different materials and for different threshold energies $\left({ }^{10}\right.$ ). In the case of pure molybdenum, the CEEXAFS signal is characteristic of about $300 \mathrm{~nm}$ depth. Then, since our samples are $70 \mathrm{~nm}$ thick, we are certain to probe the whole sample. We can also point out from CEEXAFS results that there is no significant variation in the different MSRD factors between implanted and non implanted specimens. The topological local order existing in the immediate neighbouring of the molybdenum atoms seems not affected by the damage created by ions implantation. Implantation induces an incomplete phase transformation from bcc to fcc structure.

From TEM results one can conclude that the molybdenum fcc phase, already observed in the $\mathrm{Xe}^{+}$ implanted samples is also induced by $\mathrm{Ar}^{+}$implantation, but, in this last case there is no diffraction pattern on the diffraction image that could indicate the presence of Ar bubbles. Two hypothesis can be formulated : if argon bubbles are not created the above explanation is no longer valid and the fcc molybdenum structure is not induced between rare gas bubbles and bcc molybdenum matrix and then the mechanism is not clearly understood. It seems more reasonable to think that argon solid bubbles are created, inducing fcc molybdenum phase formation, then, the intensity of solid argon ring in the diffraction pattern is too weak to be detected; only a small percentage of the volume is occupied by the solid bubbles, and the elastic stresses could be sufficient to bring about the formation of the fcc phase in the film. The internal stresses are going to be measured by $X$-ray diffraction using the $\sin ^{2} \Psi$ method.

\section{Acknowledgements}

The authors are pleased to thank M.F. Denanot and C. Boisseau for performing TEM and evaporation experiments.

\section{References}

/1/ M. Jaulin, G. Laplanche, J. Delafond and S. Pimbert, Surf. Coat. Technol. 37 (1989) 477.

12/ J.F. Ziegler, J.P. Biersack and V. Littmark The stopping and range of ions in solids, Pergamon, N.Y. (1988)

/3/ G. Tourillon, E. Dartyge, A. Fontaine, M. Lemonnier and F. Bartol, Phys. Lett. A121 (1987) 251.

/4/ J. Mimault to be published in Material and Sciences Technology

15/ P. Chartier, J. Mimault, T. Girardeau, M. Jaouen and G. Tourillon, Journal of Alloys and Compounds 194 (1993) 77-85

/6/ P. A. Lee and J. B. Pendry, Phys. Rev. B, 11 (1975) 2795.

77/ A. G. McKale, G. S. Knapp and S. K. Chan, Phys. Rev. B, 33 (1986) 841.

/8/ J.F. Dinhut and M.F. Denanot submitted for publication in Materials Letters

19/ P.S. Aggawal and Goswami Proc. Phys. Soc. Vol 70 (1957) p 708

/10/ T.Girardeau, J. Mimault, M. Jaouen, P. Chartier and G. Tourillon, Phys. Rev B 46, 11, (1992), 7144-7152 